SCADioc

International Journal of Dentistry and Oral Science (IJDOS)

ISSN: 2377-8075

\title{
Comparison Of Post-Operative Pain After Pulpectomy Using Kedo-S Square File, Hand H File and K File - A Randomized Controlled Trial
}

Research Article

Lakshimi Lakshmanan ${ }^{1 *}$, Ganesh Jeevanandan ${ }^{2}$

${ }^{1}$ Post Graduate Student Department of Pediatric and Preventive Dentistry, Saveetha Dental College, Saveetha Institute of Medical and Technical Science, Chennai, Tamil Nadu, India.

${ }^{2}$ Reader Department of Pediatric and Preventive Dentistry, Saveetha Dental College, Saveetha Institute of Medical and Technical Science, Chennai, Tamil Nadu, India.

\section{Abstract}

Introduction: Biomechanical preparation using conventional hand files or rotary files plays a significant role in the pulpectomy procedure. The objective of this study was to compare the post-operative pain after root canal instrumentation with Kedo-S Square rotary files, hand $\mathrm{H}$-files and $\mathrm{K}$-files in primary molar teeth.

Materials and methods: A randomized clinical trial was performed on 45 primary molars equally distributed for instrumentation with Kedo-S Square files, H-files and K-files. After completion of pulpectomy, the post-operative pain was evaluated at intervals of 6,12, 24 and 48hours using modified Wong Baker pain scale and compared between the groups.

Results: In all three groups, the highest post-operative pain scores were recorded at 6-hour interval and decreased over time. There was decreased post-operative pain with Kedo-S Square rotary files (26.6\%) as compared to K-filegroup (66.7\%) and H-file group $(80 \%)(\mathrm{P}<0.05)$.

Conclusion: The least post-operative pain was found in Kedo-S Square file group followed by K-file group and H-file group.

Keywords: Post-Operative Pain; Primary Teeth; Pulpectomy; Root Canal Treatment; Rotary File.

\section{Introduction}

The role of a pedodontist is to conserve the integrity of primary teeth and their supporting tissues until normal exfoliation, as natural tooth is contemplated as the best space maintainer [1]. Early loss of primary tooth can not only lead to alteration in permanent tooth eruption pathway, development of aberrant habits, variation in phonation and aesthetic problems, but also prevent psychological effects associated with tooth loss $[2,3]$.

Pulpectomy is the favorable choice of treatment for the primary tooth with chronic inflammation involving radicular pulp or withpulp necrosis [4]. The success of pulpectomy confides on aseptic root canal preparation and hermetic seal of the canals. The bio-mechanical preparation (BMP) plays apredominant role in determining the success of pulpectomy $[5,6]$. Over the years, hand files were used for root canal preparation in primary teeth, but has resulted in iatrogenic errors and also reported to be more time consuming $[7,8]$. Apart from scrupulous cleaning and debridement of the canals, the time taken for the treatment holds significance in pediatric dentistry.

With technological upgrading, there is a dynamic transition from the use of hand instrumentation to rotary systems for bio-mechanical preparation in primary root canals. Ni-Ti rotary filesshortened the instrumentation time and established conical shaped canals by adequate dentin removal ensuring sufficient root canal cleaning and shaping with minimal risk of transportation [5, 9]. Drukteinis and Balciuniene stated incomplete cleaning of the isthmus and fins of primary teeth by rotary instruments due to

*Corresponding Author:

Lakshimi Lakshmanan,

Post Graduate Student Department of Pediatric and Preventive Dentistry, Saveetha Dental College, Saveetha Institute of Medical and Technical Science, 162, Poonamallee High

Road, Chennai-600 077, Tamil Nadu, India.

Tel: +91 8939346341

Email Id: lachulaxmanan@gmail.com

Received: March 18, 2021

Accepted: April 03, 2021

Published: April 08, 2021

Citation: Lakshimi Lakshmanan, Ganesh Jeevanandan. Comparison Of Post-Operative Pain After Pulpectomy Using Kedo-S Square File, Hand H File and K File - A Randomized Controlled Trial. Int J Dentistry Oral Sci. 2021;08(04): 2272-2276. doi: http://dx.doi.org/10.19070/2377-8075-21000449

Copyright: Lakshimi Lakshmanan 2021 . This is an open-access article distributed under the terms of the Creative Commons Attribution License, which permits unrestricted use, distribution and reproduction in any medium, provided the original author and source are credited. 
the centering of rotary files in the canal. To overcome this disadvantage, $\mathrm{H}$-files can be used to remove the infected tissue from the ribbon shaped canals [10]. Various researchers have compared the different rotary file systems and hand instrumentations based on cleaning potency, instrumentation time and quality of obturation, each technique having its own pros and cons $[5,9,11]$.

A brief complication is the post-operative pain, that commence within few hours or days after pulpectomy. Post-operative pain is characterized by the sensation of discomfort after endodontic therapy [12]. The multifactorial etiology of post-operative pain includes age, pulpal and peri-radicular status, type of tooth, pre-operative pain and technical conditions. The substantial factor being the instrumentation technique, which can evoke an acute periapical inflammatory response secondary to mechanical, chemical and microbial damage to periradicular tissues. The only variable that can be controlled by the operator is the technical factor, which includes the instrumentation, irrigation and obturation protocol $[12,13]$. The variability in the cutting and cleaning efficiency between rotary files, K-file and H-file, alters the effectiveness of cleaning and extrusion of debris.

Kedo-S Square file system (ReeGanz Pvt Ltd) is the only single file rotary system that has been introduced recently and indigenously designed for primary root canals. No studies have evaluated its effect on post-operative pain. Therefore, the current study aims to compare and evaluate the post - operative pain after pulpectomy using Kedo-S Square files, K-files and H-files in primary molars.

\section{Materials and Methods}

The ethical approval for this randomized clinical trial was given by the Institutional Review Board of Saveetha Institute of Medical and Technical Sciences (SRB/ MDS/PEDO/19-20/2). Participation in the study was voluntary and informed consent was obtained from all the parents/guardians on behalf of the children, after giving detailed information regarding the study.

\section{Sample Size and Selection Of Participants}

Based on data from a previous study ${ }^{14}$, the sample size of 45 was acquired with $95 \%$ power using a power analysis. Inclusion criteria were as follows: (1) Children aged between 4-6 years requiring pulpectomy in any of the primary mandibular molars; (2) with no significant medical condition; (3) no intake of analgesics 12 hours prior to treatment; (4) presence of sufficient coronal structure and minimum of $2 / 3$ rd root structure; (5) absence of sinus tract and pathological root resorption.

Enrollment, allocation and analysis of participants are shown in [Figure 1].

Based on a computer-generated block randomization method, the selected teeth were randomly allocated to the three groups and instrumentation was done using:

Group A (15 teeth): Kedo-S Square rotary file (Reeganz Dental Care Pvt. Ltd. India),

Group B (15 teeth): ConventionalH-file (Mani, Tochigi, Japan),

Group C (15 teeth): Conventional K- file (Mani, Inc. Tochigi, Japan).

\section{Clinical Procedure}

A single visit pulpectomy was performed by a single pediatric dentist who was familiar in using the different file systems that are used in the present study. The participants were blinded for the protocol used. Pre-operative digital intraoral periapical radiograph was obtained prior to the start of the treatment. Local anesthesia with 2\% Lignocaine with 1:2,00,000 adrenaline (LOX* 2\% adrenaline, Neon Laboratories limited India) using a $2 \mathrm{ml}$ syringe (UNILOCK single use syringe, Hindustan Ltd., Chennai, India) secured to a 25 -gauge $20 \mathrm{~mm}$ needle was administered. The tooth was isolated using rubber dam (GDC marketing, India) after the effect of local anesthesia has been confirmed. Following the initial caries removal, access opening was done with no.6 round carbine bur (Dentsply, USA) using high speed hand piece. Deroofing of the pulp chamber was done using safe ended tungsten carbine bur (Endo-Z, FG, Dentsply Maillefer, USA) with outward brushing motion. The canal patency was determined using No.10

Figure 1. Participant enrollment, allocation and analysis.

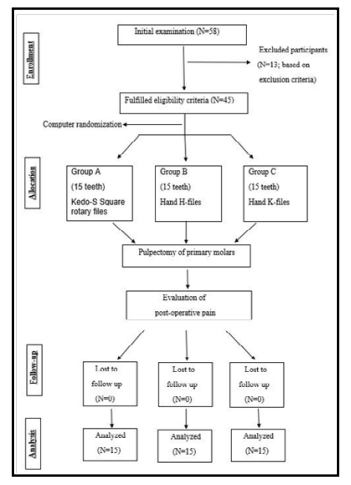

Figure 2. Modified Wong-Baker Pain Rating Scale.

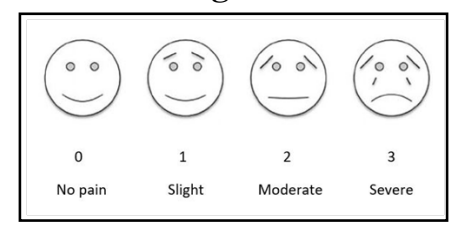


size K-file. Working length was established with pre-operative radiograph using Ingle's method.

The biomechanical preparation was performed according to the randomization sequence of the three groups. In group $\mathrm{A}$, the canals were instrumented using Kedo-S Square rotary files (Reeganz Dental care Pvt. Ltd., India) till the working length with an XSmart endodontic motor (Dentsply Maillefer, OK, USA) at 300 $\mathrm{rpm}$ and $2.2 \mathrm{~N} \mathrm{~cm}$ torque.In group $\mathrm{B}$, manual instrumentation was carried out in sequence using No.15 to 30stainless steelH-files (Mani, Inc, Tochigi, Japan) with quarter turn pull technique. In group $\mathrm{C}$, manual instrumentation was carried up to no. 35 stainless steel K-file (Mani, Inc, Tochigi, Japan) with retraction technique.

The canals were irrigated with $1 \%$ sodium hypochlorite followed by normal saline between each instrumentation sequence. After drying the canals using no.30 paper points (Dentsply Maillefer, USA), the root canals were obturated with Metapex (Meta Biomed Co. Ltd. Chungbuk, Korea).The obturation quality was acknowledged by periapical radiograph and the teeth were then restored with type II Glass ionomer cement (GC, India).

\section{Assessment Of Post-Operative Pain}

The post-operative pain was recorded using Modified Wong-Baker Pain Rating Scale as given by Topçuoğlu et al [14]. The 4-point scale measures pain as: (1) zero-no pain, (2) one-slight pain, (3) two-moderate pain, (4) three-severe pain [Figure 2]. The parents/ guardians who were blinded of the treatment protocol, were instructed on how to use this pain scale and were advised to record the pain status every $6,12,24$ and 48 hours. These data were recorded by the observer through telephonic communication with the parents/guardians at 6,12,24 and 48 hours.

\section{Statistical Analysis}

The data recorded were analyzed using SPSS software version 17.0 (SPSS Inc., Chicago, IL, USA). Chi square test was performed to compare the pain proportions between the three groups. Statistical significance was defined at $\mathrm{P}<0.05$.

\section{Results}

A total of 45 children were included in the study, among which 22 were males and 23 were females with mean age of $6.12+1.45$ years.

[Table 1] describes the mean post-operative pain scores for the three groups at different time intervals. None of the participants reported severe pain, at any of the time intervals assessed. At 6-hour, the intensity of pain experienced by participants in the hand file groups (group 2 and 3) were significantly higher than in

Table 1. Mean post-operative pain scores for Kedo-S Square file, H-File, K-File instrumentation at different time intervals.

\begin{tabular}{|c|c|c|c|}
\hline Time interval (in hours) & Kedo-S Square File & H-File & K-File \\
\hline 6 & 1.33 & 4 & 3.33 \\
\hline 12 & 0.33 & 2.33 & 1.33 \\
\hline 24 & 0 & 0.66 & 0.33 \\
\hline 48 & 0 & 0 & 0 \\
\hline
\end{tabular}

Table 2. Frequency and Percentage of Post-Operative Pain in patients receiving treatment from Kedo-S Square file, $\mathrm{H}-\mathrm{file}$ and K-file at 6-hour interval.

\begin{tabular}{|c|c|c|c|c|c|c|c|}
\hline \multirow{2}{*}{ Pain after 6 hours } & \multicolumn{2}{|c|}{ Kedo-S Square File } & \multicolumn{2}{|c|}{ H-File } & \multicolumn{2}{|c|}{ K-File } & \multirow{2}{*}{ P value } \\
\cline { 2 - 7 } & $\mathbf{N}$ & $\mathbf{0}$ & $\mathbf{N}$ & $\mathbf{\%}$ & $\mathbf{N}$ & $\mathbf{\%}$ & \\
\hline No pain & 11 & 73.3 & 3 & 20.0 & 5 & 33.3 & \\
\hline Slight & 1 & 6.7 & 3 & 20.0 & 3 & 20.0 & \multirow{2}{*}{$0.001^{*}$} \\
\hline Moderate & 3 & 20.0 & 9 & 60.0 & 7 & 46.7 & \\
\hline Severe & 0 & 0 & 0 & 0 & 0 & 0 & \\
\hline Total & 15 & 100 & 15 & 100 & 15 & 100 & \\
\hline
\end{tabular}

Table 3. Frequency and Percentage of Post-Operative Pain in patients receiving treatment from Kedo-S Square file, $\mathrm{H}-$ file and K-file at 12-hour interval.

\begin{tabular}{|c|c|c|c|c|c|c|c|}
\hline \multirow{2}{*}{ Pain after 12 hours } & \multicolumn{2}{|c|}{ Kedo-S Square File } & \multicolumn{2}{|c|}{ H-File } & \multicolumn{2}{|c|}{ K-File } & \multirow{2}{*}{ P value } \\
\cline { 2 - 7 } & $\mathbf{N}$ & $\mathbf{0}$ & $\mathbf{N}$ & $\mathbf{\%}$ & $\mathbf{N}$ & $\mathbf{\%}$ & \\
\hline No pain & 14 & 93.3 & 8 & 53.3 & 11 & 73.3 & \\
\hline Slight & 1 & 6.7 & 6 & 40 & 4 & 26.7 & \multirow{2}{*}{$>0.05$} \\
\hline Moderate & 0 & 0 & 1 & 6.7 & 0 & 0 & \\
\hline Severe & 0 & 0 & 0 & 0 & 0 & 0 & \\
\hline Total & 15 & 100 & 15 & 100 & 15 & 100 & \\
\hline
\end{tabular}


Table 4. Frequency and Percentage of Post-Operative Pain in patients receiving treatment from Kedo-S Square file, H-file and K-file at 24-hour interval.

\begin{tabular}{|c|c|c|c|c|c|c|c|}
\hline \multirow{2}{*}{$\begin{array}{c}\text { Pain after 24 } \\
\text { hours }\end{array}$} & \multicolumn{2}{|c|}{$\begin{array}{c}\text { Kedo-S } \\
\text { Square File }\end{array}$} & \multicolumn{2}{|c|}{ H-File } & \multicolumn{2}{|c|}{ K-File } & \multirow{2}{*}{ P value } \\
\cline { 2 - 7 } & $\mathbf{N}$ & $\mathbf{\%}$ & $\mathbf{N}$ & $\mathbf{\%}$ & $\mathbf{N}$ & $\mathbf{\%}$ & \\
\hline No pain & 15 & 100 & 13 & 86.7 & 14 & 93.3 & \\
\hline Slight & 0 & 0 & 2 & 13.3 & 1 & 6.7 & \multirow{2}{*}{$>0.05$} \\
\hline Moderate & 0 & 0 & 0 & 0 & 0 & 0 & \\
\hline Severe & 0 & 0 & 0 & 0 & 0 & 0 & \\
\hline Total & 15 & 100 & 15 & 100 & 15 & 100 & \\
\hline
\end{tabular}

Table 5. Frequency and Percentage of Post-Operative Pain in patients receiving treatment from Kedo-S Square file, $\mathrm{H}-$ file and $\mathrm{K}$-file at 6-hour interval.

\begin{tabular}{|c|c|c|c|c|c|c|c|}
\hline \multirow{2}{*}{$\begin{array}{l}\text { Pain after } \\
48 \text { hours }\end{array}$} & \multicolumn{2}{|c|}{$\begin{array}{c}\text { Kedo-S } \\
\text { Square File }\end{array}$} & \multicolumn{2}{|c|}{ H-File } & \multicolumn{2}{|c|}{ K-File } & \multirow[t]{2}{*}{$P$ value } \\
\hline & $\mathbf{N}$ & $\%$ & $\mathbf{N}$ & $\%$ & $\mathbf{N}$ & $\%$ & \\
\hline No pain & 15 & 100 & 15 & 100 & 15 & 100 & \multirow{5}{*}{$>0.05$} \\
\hline Slight & 0 & 0 & 0 & 0 & 0 & 0 & \\
\hline Moderate & 0 & 0 & 0 & 0 & 0 & 0 & \\
\hline Severe & 0 & 0 & 0 & 0 & 0 & 0 & \\
\hline Total & 15 & 100 & 15 & 100 & 15 & 100 & \\
\hline
\end{tabular}

the Kedo-S Square group (group 1) [Table 2]. At 12-hour, there was significant difference in the post-operative pain after instrumentation with Kedo-S Square file (group 1) and H-file (group 2) [Table 3]. At 24-hour interval, there was no significant difference in the post-operative pain between the three groups $(\mathrm{P}>0.05)[\mathrm{Ta}-$ ble 4]. All the participants in all the groups did not experience any pain at 48-hour interval [Table 5]. In all three groups, the highest post-operative pain scores were recorded at 6-hour interval and decreased over time.

\section{Discussion}

Post-operative pain is apredominant factor inestablishing the clinical success of endodontic therapy in both deciduous and permanent teeth. In case of pediatric patients, post-operative pain is often intensified with increased anxiety [15]. Prevention and management of post-operative pain after endodontic therapy is a fundamental part of the dental treatment. Prudence about the expected post-operative pain and prescription of medications to the patientsnot only enhances their trust on dentist, but also increases the pain threshold of the patients and flourish their attitude towards prospective treatment [16].

Analgesics such as non-steroidal anti-inflammatory drugs and opioidsthat are commonly used for controlling post-operative pain, have been associated with side effects such as nausea, vomiting, sedation and respiratory depression [17]. In concern to this, providing optimal treatment with minimum post-endodontic pain should be the goal to achieve clinical success of the treatment.

Post-endodontic pain has multi-factorial etiology and rely upon the association between host immunological response, infection and physical impairment. During bio-mechanical preparation of the canals, dentinal residue, necrotic debris, remnant pulp tissue, irrigation solution and micro-organisms are apparently pushed into periapical tissues. Ejection of these rudiments in to periapical tissues may cause undesired effects such as inflammation, delayed healing and post-operative pain [18]. The main objective of pulpectomy is to render proper cleaning and shaping of root canals in such a way that all the debris and bacteria in corporated tissues are eradicated.

The complex anatomy and tortuous course of root canals in primary teeth made the endodontic treatment to be more challenging [19]. Hand files which were used traditionally for preparing the root canals have reported to be time consuming and resulted in various iatrogenic errors such as zipping, transportation, apical blockade. Ni-Ti rotary system gained recognition due to their high flexibility that allow them to follow the original anatomy of the root canal. Further more, the decreased preparation time and promotion of a more uniform filling resulted in paradigm shift from the use of manual files to rotary files system [7,14].

Various studies in permanent teeth have reported reduced postendodontic pain in both single and multiple visit root canal therapy with rotary instrumentation when compared to hand instrumentation $[20,21]$. Topçuoğlu et al., acknowledged the reduction in post-operative pain after pulpectomy in primary teeth with rotary instrumentation (Revo-S), that is indicated for permanent teeth [14].

The purpose of this study was to evaluate the post-operative pain after pulpectomy using Kedo-S Square files, K-files and $\mathrm{H}$-files in primary molars. The results suggest that the intensity of postoperative after pulpectomy were significantly higher in patients in the hand file group than those in the rotary file group.

Working length is a crucial parameter in determining the apical 
extrusion of debris and irritants. The working length in the current study has been estimated based on Ingle's method, which is $1 \mathrm{~mm}$ short of the radiographic apex. This methodology minimizes the risk of over instrumentation as well as the bias [22, 23]. One percent sodium hypochlorite was used as the irrigation solution in this study during canal preparation as recommended by American Academy of Pediatric Dentistry. The higher concentration of sodium hypochlorite is not recommended during root canal preparation in primary teeth because of the physiological resorption of the root resulting in open apex [24].

Rotary instrumentation using Ni-Ti rotary files utilizes crowndown technique, there by controlling the canal preparation in the apical one-third of the canal preventing apical extrusion of debris [13]. Increased extrusion of debris associated with hand instrumentation can be ascribed to the piston-like gesture of the usage of files [25]. The rotary file system used in the present study has variably variable taper that limits the apical preparation of the canal and provides a wider cervical preparation. This factor further determines the decreased post-operative pain reported in the current study with rotary system as compared to hand instrumentation.

The higher intensity of post-operative pain occurred at 6-hour interval, which might be related to the time required for the effects of the anesthetic to completely dissipate. The pain scores decreased gradually; none of the participants in rotary file groupreported any pain after 12-hour interval where as in the hand instrumentation group, the pain decreased after 24 hours. This is compatible with the data of previous studies evaluating the intensity of post-operative pain after pulpectomy at various time intervals $[26,27]$.

Further studies assessing the exact cause of pain, objective signs of pain measurement, role of different obturating materials and irrigating solutions are warranted to provide stronger evidence regarding the rationale.

\section{Conclusion}

Based on the findings of this study, it can be concluded that root canal preparation with Kedo-S Square rotary file systemcause less intense post-operative pain when compared to hand file system.

\section{References}

[1]. Attari N, Roberts JF. Restoration of primary teeth affected by Early Childhood Caries. Eur J Paediat Dent. 2004 Jun 1;5:92-7.

[2]. Takushige T, Cruz EV, Asgor Moral A, Hoshino E. Endodontic treatment of primary teeth using a combination of antibacterial drugs. Int Endod J. 2004 Feb;37(2):132-8

[3]. Goerig AC, Camp JH. Root canal treatment in primary teeth: A review. Pediatr Dent. 1983;5:33-7.

[4]. Moskovitz M, Sammara E, Holan G. Success rate of root canal treatment in primary molars. J Dent. 2005 Jan 1;33(1):41-7.

[5]. Barr ES, Kleier DJ, Barr NV. Use of nickel-titanium rotary files for root canal preparation in primary teeth. Pediatr Dent. 2000 Jan 1;22(1):77-8.
[6]. Rodd HD. UK national clinical guidelines in paediatric dentistry. Int J Paediatr Dent. 2006;1:15-23.

[7]. Revathi M, Rao CV, Lakshminarayanan L. Revolution in endodontic instruments-A review. Endodontology. 2001;13:43-50.

[8]. Glickman GN, Koch KA. 21st-century endodontics. J Am Dent Assoc. 2000 Jun 1;131(Suppl):39S-46S.

[9]. Musale PK, Mujawar SA. Evaluation of the efficacy of rotary vs. hand files in root canal preparation of primary teeth in vitro using CBCT. Eur Arch Paediatr Dent. 2013 Apr;15(2):113-20.Pubmed PMID: 23893606.

[10]. Drukteinis S, Balciuniene I. A scanning electron microscopic study of debris and smear layer remaining following use of AET instruments and K-flexofiles. Stomatologija. 2006;8(3):70-5.Pubmed PMID: 17191061.

[11]. Ochoa-Romero T, Mendez-Gonzalez V, Flores-Reyes H, Pozos-Guillen A. Comparison between rotary and manual techniques on duration of instrumentation and obturation times in primary teeth. J Clin Pediatr Dent. 2011 Jul 1;35(4):359-64.

[12]. Nekoofar MH, Sadeghipanah M, Dehpour AR. Evaluation of meloxicam (A cox-2 inhibitor) for management of postoperative endodontic pain: a double-blind placebo-controlled study. J Endod. 2003 Oct;29(10):634-7. Pubmed PMID: 14606784.

[13]. al-Omari MA, Dummer PM. Canal blockage and debris extrusion with eight preparation techniques. J Endod. 1995 Mar;21(3):154-8.Pubmed PMID: 7561660.

[14]. Topçuoğlu G, Topçuoğlu HS, Delikan E, Aydınbelge M, Dogan S. Postoperative pain after root canal preparation with hand and rotary files in primary molar teeth. Paediatr Dent. 2017 May 15;39(3):192-6.

[15]. Perković I, Perić M, ROMIĆ KNEŽEVIĆ M, JUKIĆ KRMEK S. The level of anxiety and pain perception of endodontic patients. Acta Stomatol Croat. 2014 Dec 30;48(4):258-67.

[16]. Van Wijk AJ, Hoogstraten J. Reducing fear of pain associated with endodontic therapy. International Endodontic Journal. 2006 May;39(5):384-8.

[17]. Lee JY, Jo YY. Attention to postoperative pain control in children. Korean J Anesthesiol. 2014;66:183-8.

[18]. Topçuoğlu G, Topçuoğlu HS, Akpek F. Evaluation of apically extruded debris during root canal preparation in primary molar teeth using three different rotary systems and hand files. Int J Paediatr Dent. 2016 Sep;26(5):35763.

[19]. Salama FS, Anderson RW, McKnight-Hanes C, Barenie JT, Myers DR. Anatomy of primary incisor and molar root canals. Pediatr Dent. 1992 Mar 1;14(2):117-8.

[20]. Talebzadeh B, Nezafati S, Rahimi S, Shahi S, Lotfi M, Ghasemi N. Comparison of Manual and Rotary Instrumentation on Postoperative Pain in Teeth with Asymptomatic Irreversible Pulpitis: A Randomized Clinical Trial. Iran Endod J. 2016 Fall;11(4):273-279.Pubmed PMID: 27790255.

[21]. Kashefinejad M, Harandi A, Eram S, Bijani A. Comparison of Single Visit Post Endodontic Pain Using Mtwo Rotary and Hand K-File Instruments: A Randomized Clinical Trial. J Dent (Tehran). 2016 Jan;13(1):10-7.Pubmed PMID: 27536323

[22]. Martin H, Cunningham WT. The effect of endosonic and hand manipulation on the amount of root canal material extruded. Oral Surg Oral Med Oral Pathol. 1982 Jun;53(6):611-3.Pubmed PMID: 6954443.

[23]. Reddy SA, Hicks ML. Apical extrusion of debris using two hand and two rotary instrumentation techniques. J Endod. 1998 Mar 1;24(3):180-3.

[24]. American Academy of Pediatric Dentistry. Guideline on pulp therapy for primary and immature permanent teeth. Pediatr Dent. 2012;34:222-9.

[25]. Madhusudhana K, Mathew VB, Reddy NM. Apical extrusion of debris and irrigants using hand and three rotary instrumentation systems-An in vitro study. Contemp Clin Dent. 2010 Oct;1(4):234-6.

[26]. Panchal V, Jeevanandan G, Subramanian EMG. Comparison of post-operative pain after root canal instrumentation with hand $\mathrm{K}$-files, $\mathrm{H}$-files and rotary Kedo-S files in primary teeth: a randomised clinical trial. Eur Arch Paediatr Dent. 2019 Oct;20(5):467-472.Pubmed PMID: 30864090.

[27]. Nair M, Jeevanandan G, Vignesh R, Subramanian EM. Comparative evaluation of post-operative pain after pulpectomy with k-files, kedo-s files and mtwo files in deciduous molars-a randomized clinical trial. Braz. Dent. Sci. 2018 Oct 24;21(4):411-7. 